\title{
RELATIVE POSITION OF THE SIZE OF SEDIMENTS IN THE CROSS-SHORE PROFILE
}

\author{
I. LÓPEZ ${ }^{1}$, L. ARAGONÉS ${ }^{1}$, M. LÓPEZ ${ }^{1}$, A. PALAZÓN² \& M.E. GÓMEZ-MARTÍN ${ }^{3}$ \\ ${ }^{1}$ Department of Civil Engineering, Alicante University, Spain \\ ${ }^{2}$ Department of Civil Engineering, Catholic University of Murcia, Spain \\ ${ }^{3}$ Department of Transportation, Universitat Politècnica de València, Spain
}

\begin{abstract}
Most of the beaches in the world have serious erosion problems. To solve this problem, there are different methods of beach nourishment, which consist mainly of a feedback from the beach by pouring sand and with some protection element as dikes or breakwaters. The problem arises when selecting the optimal size of sediment for nourishment. The literature suggests that sediments with similar or higher sizes than those on the dry beach should be employed for nourishment. However, this does not ensure the stability of the future profile since, it is not known how the new material will be distributed on the seabed. In this work, the evolution of the sediment size of the seabed and its position relative to the coastline is studied, using sedimentological data of 1987 and 2006 in the southern part of the province of Valencia (Spain) using a GIS system. Thus, it was observed that: i) the sediment sizes smaller than $0.063 \mathrm{~mm}$ are placed beyond the depth of closure (DoC), ii) sizes $0.180-0.125$ sediment are located between the shoreline and the $\mathrm{DoC}$, iii) while the sizes of 0.250 are located mainly near the coastline. Therefore, when performing beach nourishment on this area, a material between 0.250 and $0.180 \mathrm{~mm}$ should be used, which will ensure the stability of the profile and the sand will not cross the DoC, which would mean the loss permanently.
\end{abstract}

Keywords: beach nourishment, median sediment size, sediment distribution.

\section{INTRODUCTION}

Erosion is a problem affecting most of the world's beaches. The measure most commonly used is the so-called hard-engineering [1], although artificial nourishment of beaches consisting of sand dumping on the dry beach is more common in recent years than the construction of rigid structures, becoming the main alternative in fighting erosion processes [2]. In much of the coast of Valencia, located in eastern Spain, this type of actions has been concentrated in a short period of time, so that considering only those interventions with sand from marine dredging, a total of 29 artificial nourishment were carried out between 1985 and 1999 [3].

However, determine the median sediment size used in nourishments remains a problem. Because, when classifying a beach and representing their characteristics, it comes up the question of how to determine, for example, the median sediment size $\left(\mathrm{D}_{50}\right)$ of the beach, since along the beach there are notable difference in the grain size distribution. Bascom [4] describes how this distribution varies along the cross-shore profile towards the coast from the base of the dunes to the waterfront. The larger grains are usually found beyond the backwash/ surf interaction area, an area of great turbulence interaction. The area of the summer berm also contains significant coarse material due to the run-up dynamics. The finest material is in the dune area due predominantly to wind transport processes.

Seaward from the mean low water, sediments begin to be thinner, as the distance increases seaward of the surf zone [5]. Regarding the determination of grain size distribution of the native beach, it has been found that by combining samples from the other side of the beach and surrounding marine areas, variability in the grain size is reduced [6], therefore the grain size distribution will vary depending on the location of the samples [7]. It has also been 
reported on the varying size of sediments along the coast. The usual assumption is that the sediment size decreases in the transport direction due to selective transport, with the finest particles distancing the coarser particles [8].

McLaren [9] presented a significant improvement in trend analysis of the grain size using a combination of the three main parameters of grain size: median size, sorting and skewness. Later, McLaren and Bowles [10] developed a statistical treatment of the data of the grain size, which provided a 1-D model of the networks of the sediment transport. According to McLaren model, two patterns of effective sediment transport can be distinguished in natural environments; offshore sediments can become: i) finer, better sorting and negatively skewed, or ii) coarser, better sorting and positively skewed.

It is also known that the sediment will be best classified according to the predominant direction of sediment transport, which does not imply a relationship between transport and size. Because as described by Stauble and Cialone [11], large storms cause fine sediments moving offshore, so that when the storm abates the larger sizes are deposited, causing an increase in the median sediment size of the beach.

As we can see, there are different theories about how the sediment is distributed in the beach profile. However, no theory determines the relative position of each of the grain sizes on the profile, which is necessary when selecting the optimal size of sediments for nourishment. The literature suggests that should be used similar or superior to sizes of sediments that are on the dry beach. However, this does not ensure the stability of the future profile, since it is not known how the new material will be distributed on the seabed. Therefore, the main objective of this research is the study of the evolution of the sizes of seabed sediment and its position relative to the shoreline. Thus, determining the position in which are located each of the sizes that form the sand will allow to determine the median size of the sediment required to use in the beach nourishments to ensure the profile's stability, and that the sand does not displace to exceeding the depth of closure (DoC), which would mean the loss permanently.

\section{STUDY AREA}

The study is carried out on the south of the province of Valencia (Spain), specifically from the Port of Valencia to the province of Alicante (Fig. 1). The area has a coastline of $72 \mathrm{~km} \mathrm{com}-$ posed of sandy beaches and soft bottoms. The coastline is characterized because sediment accumulation processes predominate. The southern area of the province is made up of long open sand beaches and shallow water.

The stability of the study area may be affected on one hand by the decrease in sediment supply due to the altered flow of rivers that drain into the study area (Turia, Júcar and Serpis) or by a decrease due to drought periods or the execution of works of channeling and reservoir. And on the other hand, the existence of artificial barriers that impede sediment transport, such as the ports of Valencia and Gandía.

Regarding the waves, the dominant are from ENE with a significant wave height of $3.9 \mathrm{~m}$ and a period of $11.6 \mathrm{~s}$, while more frequent waves are those coming from $\mathrm{E}$, with wave heights of $2.8 \mathrm{~m}$ in deep water and a period of $10.5 \mathrm{~s}$ [12]. Astronomic las mareas astronómicas oscilan entre 20 y $30 \mathrm{~cm}$, que junto con las mareas meteorológicas pueden llegar a ser de hasta $75 \mathrm{~cm}[12]$.

\section{METHODOLOGY}

This work employs bathymetry, morphology and sediment data provided by the "Alicante Coastal Service" (Servicio Provincial de Costas de Alicante). 


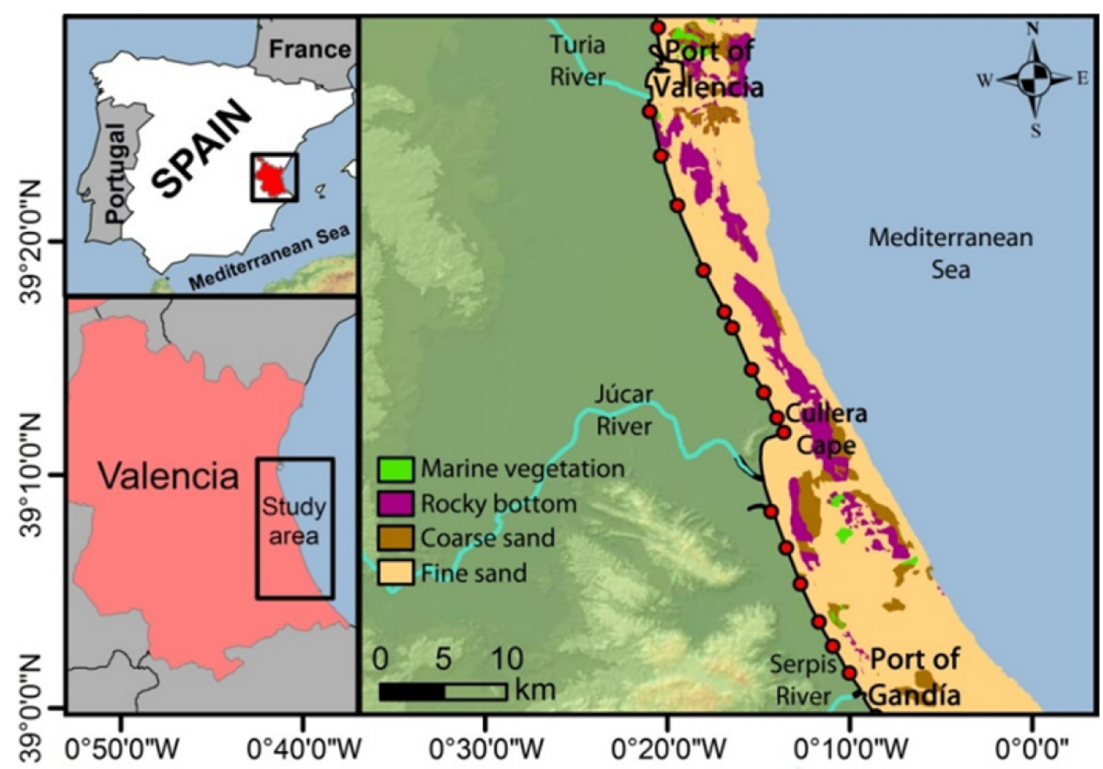

Figure 1: Location of the study area.

The data used in this study come from two sources: i) Marine Geophysical Survey [13], supplied in hard copy, so it was necessary to digitize and vectorize all the information. Seven maps that covered the whole studied area were digitized on a 1:5000 scale. ii) Estudio Ecocartográfico de las Provincias de Valencia y Alicante [12] provided in digital format.

For the 1987 study, bathymetry measurement was carried out by using a Maxiran radiopositioning system with $420-450 \mathrm{MHz}$ frequency band. Morphology was obtained from a pulse Klein side-scan sonar with $100 \mathrm{kHz}$ frequency. The data were taken from the depth $-4 \mathrm{~m}$ to $-35 \mathrm{~m}$. For the second campaign [12], several devices were used: a multibeam sounding system, swell compensator, gyroscopic compass, sound velocity sensor, differential GPS and other auxiliary elements. Data were taken from the shoreline to a depth of $-40 \mathrm{~m}$. Average precision of depth measurements was $\pm 15 \mathrm{~cm}$ for both campaigns. Finally, the sedimentology data were obtained in both campaigns by using a Van Veen dredger.

The ArcGIS Georeferencing tool was used in order to georeference the scanned maps raster datasets. The process involves the identification in the raster of a series of ground control points whose coordinates, $\mathrm{X}$ and $\mathrm{Y}$, are already known. This allows linking dataset raster location to their real spatial location. A minimum of 8 points distributed throughout the map were used for setting the coordinate system of the data frame, Geographic Coordinate System WGS84 Zone 30 N. A measurement of the error of this process was given by the Root Mean Square (RMS) error. The RMS values vary from 1.2 to 2.6 , what indicates that there is a significant accuracy taking into account the scale of the maps. Finally, bathymetric contours and sediment sample points were vectorized. Figure 2 shows the bathymetry and the sampling points in the southern part of the study area.

All the information available was homogenized and stored in a geodatabase, the distribution of sediments was studied against the study area. For this, the methodology described by Aragonés et al. [14] was followed. Thus, by using a GIS, layers were generated from the 


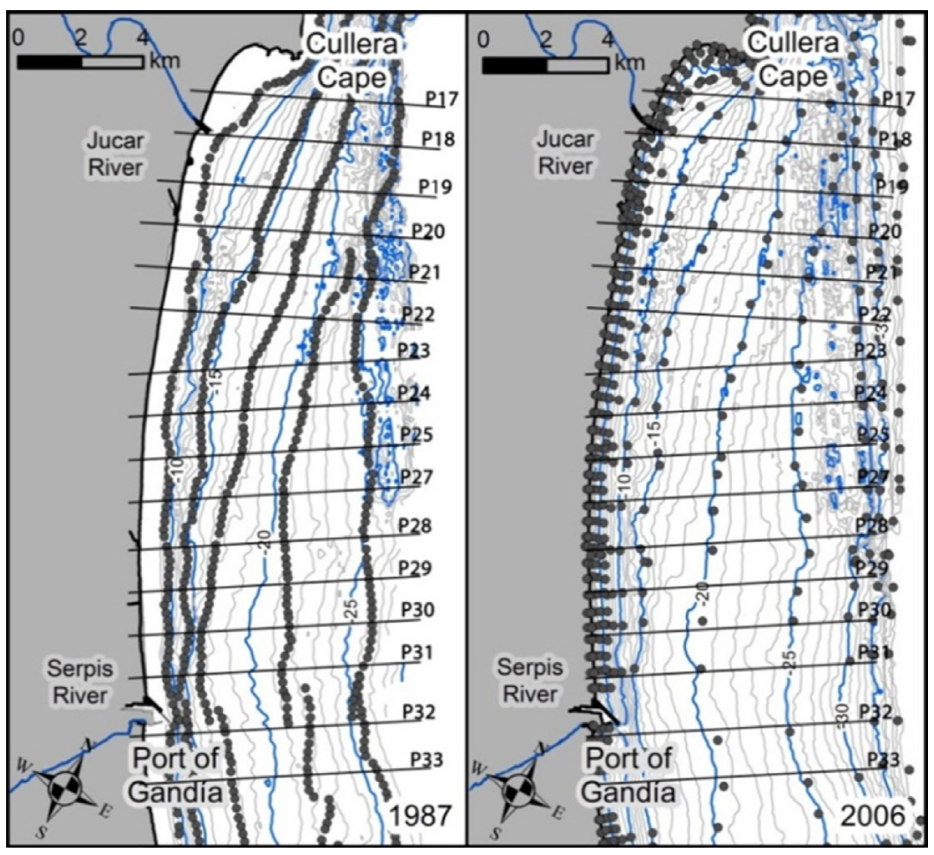

Figure 2: Location of sediment samples and comparison of the bathymetry of 1987 (left) and 2006 (right), in the southern part of the study area.

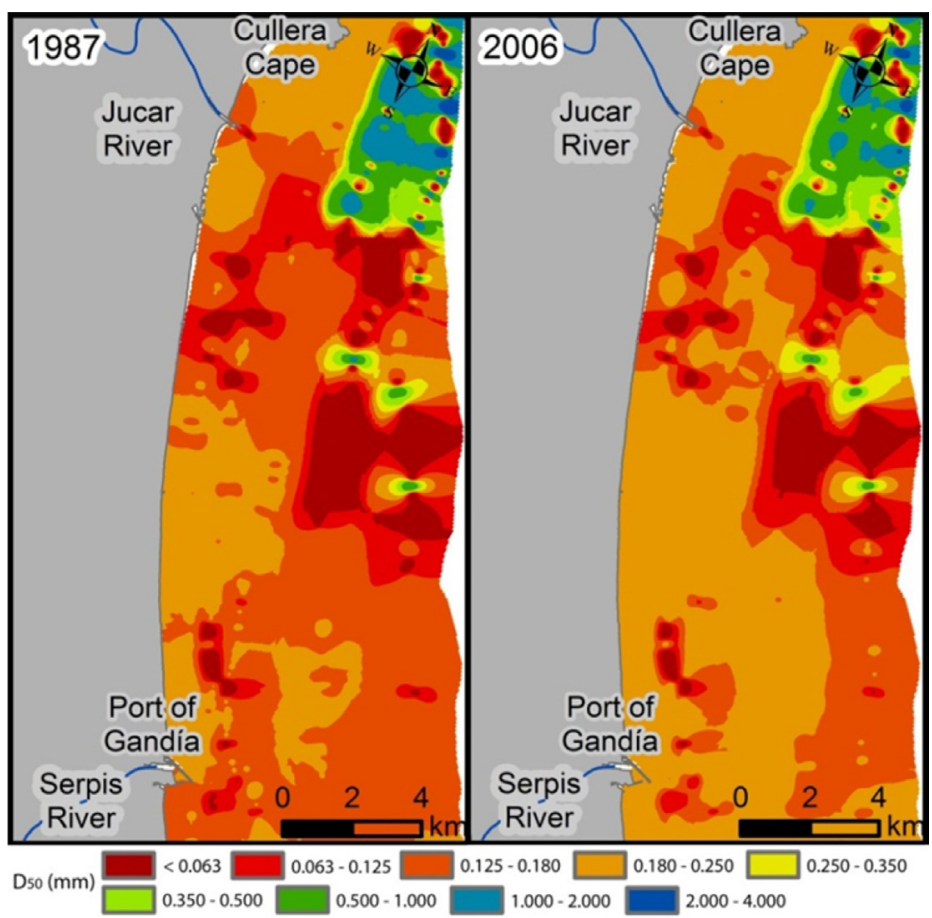

Figure 3: Comparison of the $\mathrm{D}_{50}$ in the southern part of the study area. 
spatial distribution of the sediment, both $\mathrm{D}_{50}$ and the percentage of samples retained on each sieve and the bottom morphology. Last, cross-shore profiles intersecting each of the layers were plotted.

Finally, the 1045 samples from 1987 were compared with the 1500 samples from 2006.

\section{RESULTS AND DISCUSSION}

Figure 3 shows the median sediment size distribution in 1987 and 2006. As can be seen, in 2006 there is a reduction of the fine sediments, which probably have been dragged to the abyssal plains by the waves as was proposed by Aragonés et al. [14]. Although it is still observed a certain accumulation in areas close to river mouths, perhaps due to their contribution. On the other hand, it can be seen that near the Cullera Cape, there is an accumulation of coarse sediments $(0.500-4.000 \mathrm{~mm})$, which seems logical as it is a rocky area.

In Fig. 4, it can be seen a clear decline in the finer sizes (0.063-0.125 mm) between 1987 and 2006. The proportion reaches values higher than $70 \%$ in large part of the area in 1987,

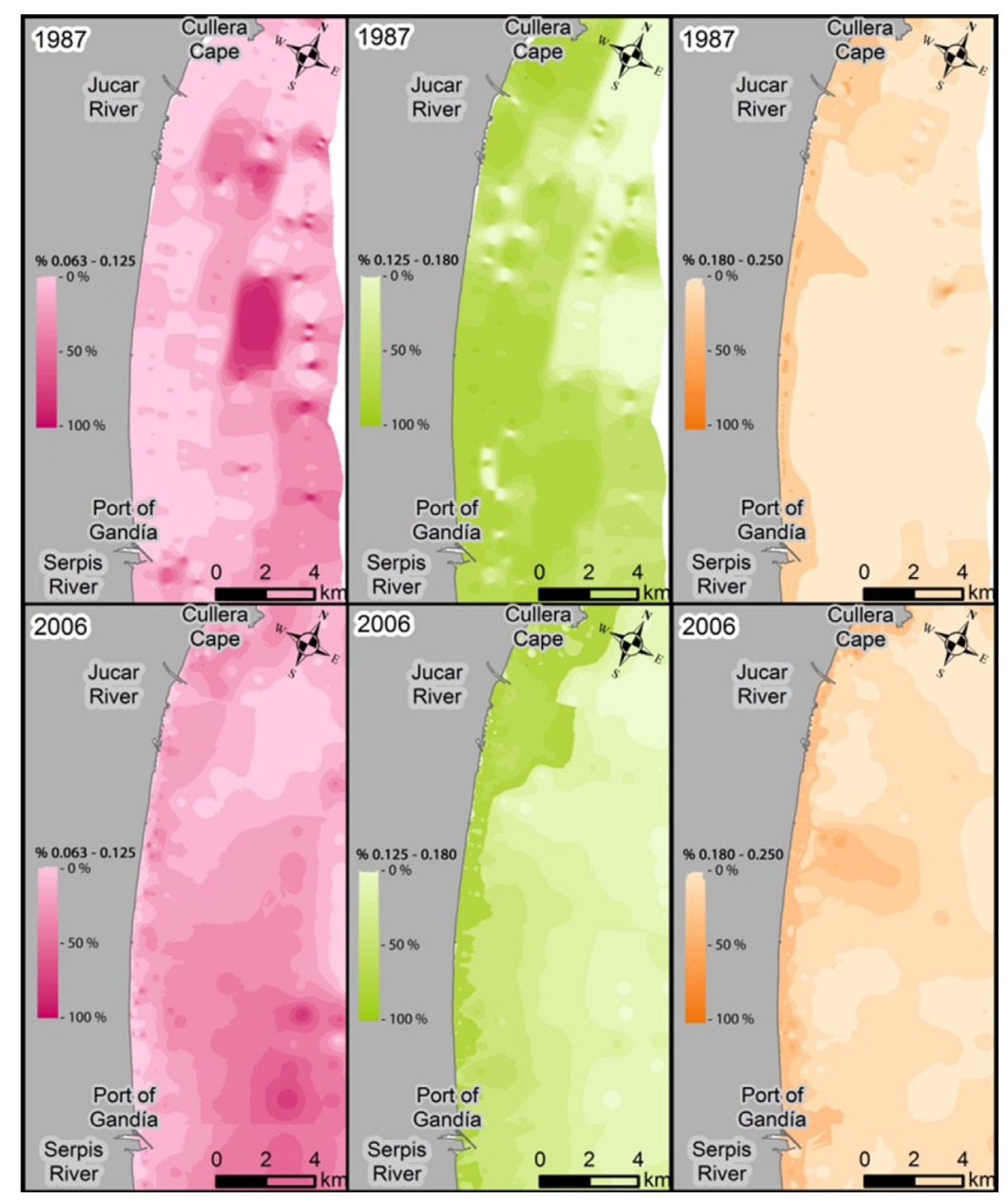

Figure 4: Comparison of percentage of material retained on the sieves $0.063,0.125$ and 0.180 in the southern part of the study area. 


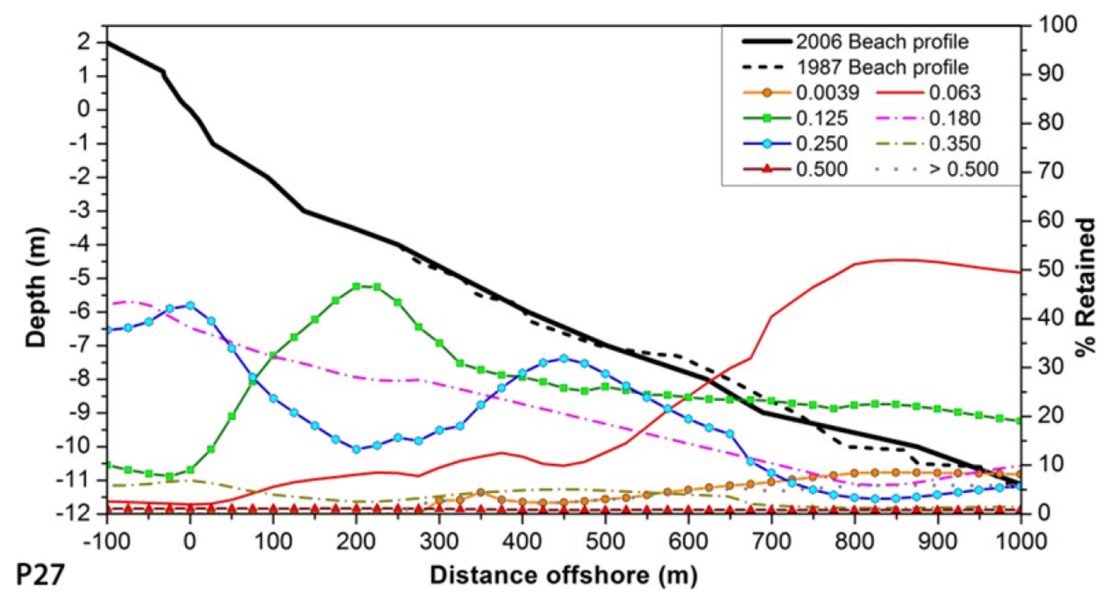

Figure 5: Percentage of the material retained on each sieve (data 2006) along the cross-shore beach profile.

while in 2006 the proportion is lower than 50\%. Regarding the sizes between 0.125 and $0.250 \mathrm{~mm}$, the higher concentration is near the coastline in both periods, although there is a small diminution in sizes $0.125-0.180 \mathrm{~mm}$ in 2006 in the off-shore zone.

Finally, the distribution of each of the sieves along the cross-shore beach profiles is shown (Fig. 5). These results show that the cross-shore profiles have remained stable between 1987 and 2006. Moreover confirm what has already been seen in Fig. 4, the thicker sizes are usually found near the coastline. Specifically, are the sizes of $0.250 \mathrm{~mm}$ and $0.180 \mathrm{~mm}$ which are placed on the dry beach and surf zone, while the sizes of $0.125 \mathrm{~mm}$ are mainly located in the surf zone, without crossing the DoC. On the other hand, when it exceeds the DoC $(\approx-6 \mathrm{~m})$, sizes of $0.063 \mathrm{~mm}$ considerably increase, which will be transported off-shore by the big storms, with a low probability of returning to the dry beach.

\section{CONCLUSION}

The present investigation was initiated to know the evolution of the size of seabed sediments and their relative position with respect to the shoreline. This study has revealed what sizes are positioned in close proximity to the shoreline on the side of the wet beach, and their relationship to those immediately present on the side of the dry beach.

After thorough and extensive analysis on the number of samples performed, it is found that in most of the beaches regardless of their orientation, and except for specific cases close to sediment supply (river mouths), or the shelter of morphological accidents, is repeated the same pattern of behavior. The trend is that all sediments of the smaller sizes (silts and clays), $0.0039 \mathrm{~mm}$ and $0.063 \mathrm{~mm}$, respectively, are positioned beyond the accretionary limit or DoC, limit from which the sediment does not return to the coastal. Fine sands $(0.125 \mathrm{~mm})$ move in the surf zone, between the shore and the DoC, while larger sediments $(0.180-0.250 \mathrm{~mm})$ are positioned close the shoreline, and as verified in the analysis do not suffer significant displacements.

Consequently, the appropriated sediment to perform a nourishment in the Valencian coast are sand of size $0.180 \mathrm{~mm}$ or more, since the position of these sediments on the profile hardly 
varies. The use of these sizes can ensure the stability of the profile, since according to the study, they will not cross the DoC, which would imply their permanent loss.

The proper place to deposit these sediments would be in the bar area, where each size will displacing to its position within the cross-shore profile [15], placing sizes $0.180 \mathrm{~mm}$ and $0.250 \mathrm{~mm}$ near the shoreline. Furthermore, if the nourishment material supply is located on the dry beach, must be taken into account that the fine fraction $(<0.125 \mathrm{~mm})$ will disappear off-shore in a short period of time, so the shoreline will move backward.

\section{ACKNOWLEDGEMENTS}

The authors want to thank the Jefatura Provincial de Costas de Alicante for the information they provided has enabled this study.

This research has been partially funded by Universidad de Alicante through the project "Estudio sobre el perfil de equilibrio y la profundidad de cierre en playas de arena" (YGRE15-02).

\section{REFERENCES}

[1] Ng, K., Phillips, M.R, Borges, P., Thomas, T., August, P., Calado, H. \& VelosoGomes, H., Maintaining a way of life for São Miguel Island (the Azores archipelago, Portugal): An assessment of coastal processes and protection. Science of the Total Environment, 481, pp. 142-156, 2014.

https://doi.org/10.1016/j.scitotenv.2014.01.067

[2] Hamm, L., Capobianco, M., Dette, H., Lechuga, A., Spanhoff, R. \& Stive, M., A summary of European experience with shore nourishment. Coastal Engineering, 47(2), pp. 237-264, 2002. https://doi.org/10.1016/S0378-3839(02)00127-8

[3] BEACHMED, INTERREG III - MEDOCC - BEACHMED. European Project. Strategic management of beach protection for sustainable development of Mediterranean coastal zones.: Eurpean Union. Universidad Pilitécnica de Valencia, p. 553, 2003.

[4] Bascom, W.N., The relationship between sand size and beach-face slope. American Geophysical Union Transactions, 32(6), pp. 886-874, 1959.

[5] Single, M. \& Hemmingsen, M., Mixed sand and gravel barrier beaches of South Canterbury, New Zealand. In Ecology and Geomorphology of Coastal Shingle, eds J.R. Packman, R.E. Randall, R.S.K. Barnes \& A. Neal, Westbury Academic and Scientific Publishing: Otley, England, pp. 261-276, 2001.

[6] Hobson, R.D., Review of Design Elements for Beach-Fill Evaluation, DTIC Document, 1977.

[7] Stauble, D., Hansen, M. \& Blake, W., An assessment of beach nourishment sediment characteristics. Coastal Engineering Proceedings, 1(19), 1984.

[8] Horn, D.P. \& Walton S.M., Spatial and temporal variations of sediment size on a mixed sand and gravel beach. Sedimentary Geology, 202(3), pp. 509-528, 2007. https://doi.org/10.1016/j.sedgeo.2007.03.023

[9] McLaren, P., An interpretation of trends in grain size measures. Journal of Sedimentary Research, 51(2), 1981.

[10] McLaren, P. \& Bowles D., The effects of sediment transport on grain-size distributions. Journal of Sedimentary Research, 55(4), 1985. 
[11] Stauble, D.K. \& Cialone, M.A., Ebb shoal evolution and sediment management techniques Ocean City Inlet, Maryland. Proceedings 9th National Conference on Beach Nourishment. pp. 209-224, 1996.

[12] Ecolevante, Estudio ecocartográfico de las provincias de Valencia y Alicante, D.G.d. Costas, (ed) Ministerio de Medio Ambiente, 2006.

[13] MOPU, Estudio Geofísico Marino entre el Puerto de Denia y el Puerto de Valencia, Programa de Planeamiento de Actuaciones en la costa. Dirección General de Costas (España), 1987.

[14] Aragonés, L., Pagán, J.I, López, M.P. \& García-Barba, J., The impacts of Segura River (Spain) channelization on the coastal seabed. Science of the Total Environment, $\mathbf{5 4 3}$ (Part A), pp. 493-504, 2016.

[15] Guillén, J. \& Hoekstra, P., Sediment distribution in the nearshore zone: grain size evolution in response to shoreface nourishment (Island of Terschelling, The Netherlands). Estuarine, Coastal and Shelf Science, 45(5), pp. 639-652, 1997.

https://doi.org/10.1006/ecss.1996.0218 